Keio J. Med. 24: $335-346,1975$

\title{
APPLICATION OF T AND B CELL MARKERS IN THE ANALYSIS OF IMMUNODEFICIENCY STATUS
}

\author{
J. YATA, I. TSUKIMOTO, T. NAKAGAWA and T. SHIMBO \\ Department of Pediatrics, Toho University, Tokyo
}

\begin{abstract}
SUMMARY
Presence of human thymus lymphocyte antigen (HTLA) detected by immunofluorescence, spontaneous rosette formation with sheep erythrocytes ( $\mathrm{E}$ rosette), rosette formation with erythrocytes sensitized with $19 \mathrm{~S}$ antibody and complement (EAC rosette) and cell surface immunoglobulin by membrane immunofluorescence (S-Ig) were used to characterize lymphocyte subpopulations.

S-Ig positive cell was absent while the lymphocytes with $\mathrm{C} 3$ and/or IgG.Fc receptors were observed in $20-30 \%$ in 11 cases of infantile agammaglobulinemia. 11 patients with severe combined immunodeficiency were tested. They were quite heterogenous in respect to the numbers of lymphocytes having $T$ or $B$ cell markers; almost only null cells were observed in some and a number of $\mathrm{B}$ or/and $T$ cells were present in other, although both cell mediated and humoral immune responses were impaired in all.

6 selective IgA deficiency showed different IgA-B cell profile. IgA-B cells were decreased in 2 , normal in 3 and increased in 1 .

Numbers of $\mathrm{T}$ and $\mathrm{B}$ cells were quite normal in most of 17 patients with variable immunodeficiency, though their functions as judged by delayed hypersensitivity in vitro PHA response, and humoral antibody responses were sometimes impaired.

Although immunodeficiency status is not homogenous in ataxia telangiectasia, in vitro PHA response and delayed hepersensitivity reaction were impaired and absolute number of $\mathrm{T}$ cells were decreased in 4 cases tested.

Cytoxan reduced selectively $\mathrm{B}$ cells in the peripheral blood.

ACTH influenced on circulating $T$ cells probably via adrenal steroids. Reduction of $\mathrm{T}$ cells seemed due mostly to sequestration of these cells,

$\mathrm{T}$ cell reduction in blood was observed in various viral infections, especially in measles. Disappearance of circulating $\mathrm{T}$ cells by measles infection seemed to be caused at least partly by also sequestration.
\end{abstract}




\section{INTRODUCTION}

Immunodeficiency can develop by various reasons; block of the development of either $\mathbf{T}$ cells, $\mathbf{B}$ cells or both at a certain stage of their ontogeny, functional defect of these cells, depletion or sequestration of immune competent cells by exogenous agents. In order to analyse these defect, the numbers and the functions of $\mathrm{T}$ and $\mathrm{B}$ cells should be estimated separately. The circulating $\mathrm{T}$ and $\mathrm{B}$ cells from various types of primary and secondary immunodeficiency disorders were numurated by several cell markers in this study.

\section{MATERIALS AND METHODS}

1. Lymphocytes:

The lymphocytes were separated from the heparinized peripheral blood by Conray-Ficoll (SG 1077) density gradient.4

2. Rosette formation with sheep erythrocytes (E-rosette):

$5 \times 10^{5}$ lymphocytes and $2 \times 10^{7}$ sheep erythrocytes were suspended in $0.2 \mathrm{ml}$ of fetal calf serum in a small test tube. The cells were centrifuged at $200 \mathrm{~g}$ for 5 minutes and incubated in ice water for 1 hour. The pellets were gently resuspended and the percentage of rosette forming lymphocytes was scored under a light microscopy. 4 The cells were smeared on a glass slide, Giemsa stained and contaminating monocytes or granulocytes were counted at the same time. The percentage of rosette positive lymphocytes was corrected based on the proportion of contaminating cells.

3. Human thymus-lymphoid tissue antigen (HTLA):

Anti-HTLA serum was prepared as described previously. ${ }^{5}$ The lymphocytes were stained by indirect immunofluorescence and the percentage of fluorescent lymphocytes were counted under a UV-microscope.

4. Cell surface immunoglobulin (S-Ig) :

$0.05 \mathrm{ml}$ of anti-human immunoglobulin ( $\mathrm{IgM}, \mathrm{IgG}, \mathrm{IgA}$ ) fluorescent antibody the concentration of which gave maximal percentage of S-Ig positive lymphocytes in the previous study was added to $5 \times 10^{5}$ lymphocytes. The cells were incubated at $4^{\circ} \mathrm{C}$ for 30 minutes and washed three times with phosphate buffered saline (PBS). The percentage of the cells which showed cell surface attached fluorescence was scored under a UV-microscope.

5. Rosette formation with the erythrocytes sensitized with 195 antibody and complement (EAC-Rosette) :

Sheep erythrocytes were sensitized with rabbit anti-sheep erythrocyte $19 \mathrm{~S}$ antibody and reacted with $1: 10$ diluted mouse fresh serum as a complement source as described previously. ${ }^{6} 2 \times 10^{7}$ thus prepared complement sensitized 
erythrocytes (EAC) were mixed with $5 \times 10^{5}$ lymphocytes in $0.2 \mathrm{ml}$ of PBS. The cells were incubated at $37^{\circ} \mathrm{C}$ for 1 hour and at room temperature for another hour. Percentage of the lymphocytes which formed rosettes with EAC was estimated.

6. Primary immunodeficiency:

43 patients with various types of the disease were studied.

7. Effect of Cyclophosphamide:

$2 \mathrm{mg} / \mathrm{kg}$ body weight of Cytoxan was administered every day to the patients with nephrotic syndrome.

8. Effect of synthetic ACTH:

$0.7 \mathrm{mg} / \mathrm{m}^{2}$ of synthetic ACTH-Z was injected intramascularly every day to the patients with infantile spasms for a few weeks. The blood was taken just before the each injection and tested.

9. Viral infections:

The patients suffering measles were especially studied in acute or convalescent stages.

\section{RESULTS}

1. Primary immunodeficiency diseases.

1) Severe combined immunodeficiency:

11 cases were studied. Case 2 and 3 were brothers and case 4 and 5 were brother and sister. Severe lymphocytopenia was observed in all except case 5, 6 and the proportion of the lymphocytes having $\mathrm{T}$ or $\mathrm{B}$ cell markers were extremely reduced in these cases with lymphocytopenia and therefore most of the remaining lymphocytes seemed to be not competent. Normal number of lymphocytes with $\mathrm{T}$ cell markers was observed in case 5, however in vitro responsiveness of the lymphocytes to phytohaemagglutinin (PHA) and the delayed hypersensitivity skin reaction to various antigens were impaired. Therefore these $T$ cells were not like those antigen-responsive.

Case 6 had rather inereased number of the lymphocytes with surface immunoglobulin and complement receptor. Nevertheless serum immunoglobulin level was quite low and antibody response to various antigens was impaired. $\mathrm{T}$ cells were slightly decreased, in vitro PHA response was severely reduced and delayed skin hypersensitivity reaction to dinitrochlorbenzene (DNCB) was not observed. (Fig. 1)

2) Infantile X-linked agammaglobulinemia:

Surface immunoglobulin positive lymphocytes were extremely decreased in all 11 patients tested. The lymphocytes with the receptor for complement were ob- 


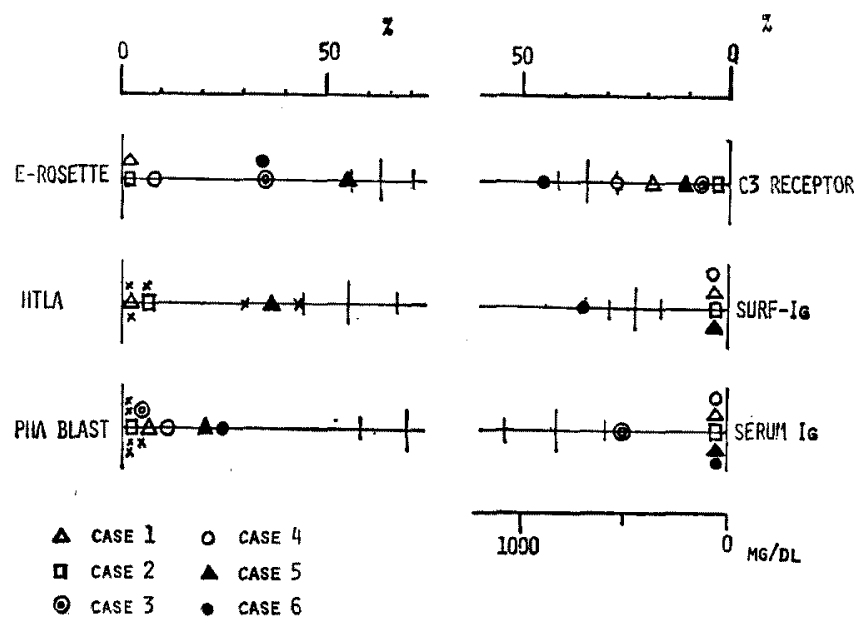

Fig. 1 Lymphocyte subpopulations in severe combined immunodeficiency.

served in $20 \sim 30 \%$. These complement receptor positive cells were cytochemically studied. Peroxydase was not detected, while arylsulfatase was stained in the nucleus. Binding of EAC to these cells was not blocked by the presence of EDTA as in the monocytes. (Fig. 2)

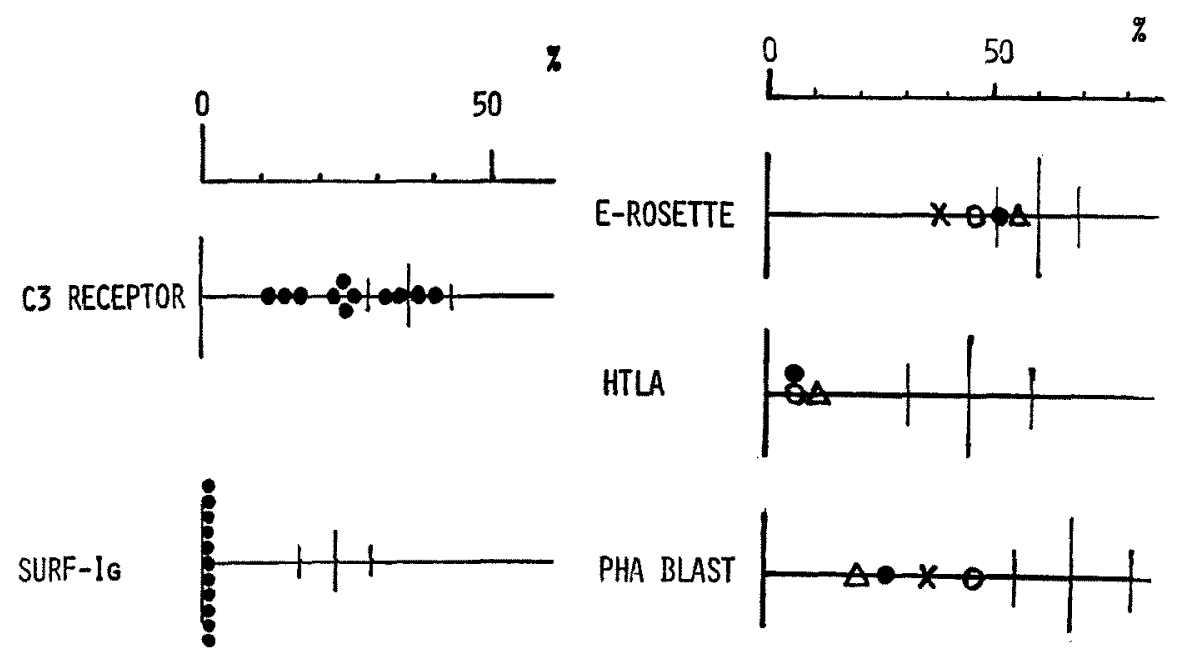

Fig. 2 B cell properties in the lymphocytes from infantile agammaglobulinemia.

Fig. $3 \mathrm{~T}$ cell properties in the lymphocytes from ataxia telangiectasia. 


\section{3) Ataxia telangiectasia:}

The percentage of E-rosette positive cells was almost normal in 2 cases and decreased in other 2. However, absolute number of these cells was reduced in all because of the lymphocytopenia. HTLA positive cells were decreased in all cases. In vitro PHA response of the lymphocytes and delayed hypersensitivity skin reaction to various antigens were impaired in all. (Fig. 3)

4) Variable immunodeficiency:

The number of the lymphocytes with each of 4 markers was quite normal in all patients tested except one who showed the decrease of HTLA positive cells. However, in vitro PHA response of the lymphocytes, delayed hypersensitivity skin reactions and serum immunoglobulin level were decreased in all patients. (Fig. 4)

5) Isolated IgA deficiency:

6 cases of isolated IgA deficiency were studied. The percentage of the lymphocytes bearing surface IgA was normal in 3, decreased in 2 and increased in 1. (Fig. 5)

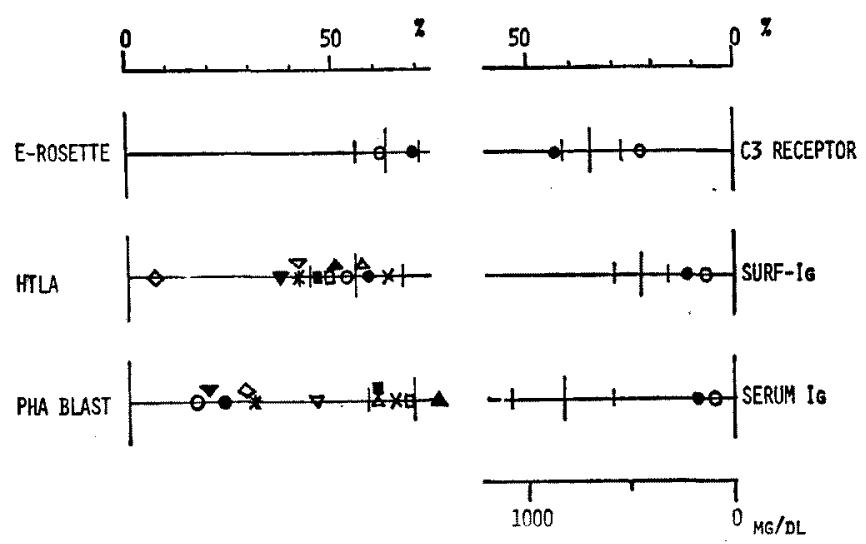

Fig. 4 Lymphocyte subpopulations in variable immunodeficiency.

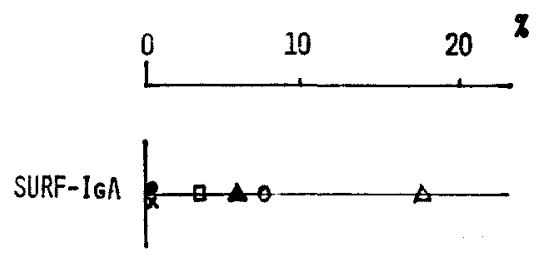

Fig. 5 Surface IgA on the lymphocytes from isolated $\operatorname{IgA}$ deficiency. 
2. Secondary immunodeficiency status.

1) Cyclophosphamide:

The absolute number of E-rosette positive lymphocytes did not change very much, while the proportion of these lymphocytes increased gradually from $60 \%$ to $80 \%$. Both absolute number and percentage of the lymphocytes forming EACrosette decreased day by day after the administration of Cytoxan. (Fig. 6)

\section{2) $\mathrm{ACTH}$ :}

The percentage and absolute number of circulating E-rosette positive lymphocytes decreased already 12 hours after the initial injection of synthetic ACTH$\mathrm{Z}$ and kept low levels as long as the injections were continued. These scores returned to the level before treatment 48 hours after disruption of injection. While, the number of the lymphocytes bearing surface immunoglobulin did not change very much during the treatment, although the percentage of these cells increased gradually. (Fig. 7)

Reverse relationship was observed between the percentage of the lymphocytes forming E-rosette and plasma cortisol level. The lower E-rosette score was observed in the individuals who showed higher cortisol level. No such a reduction
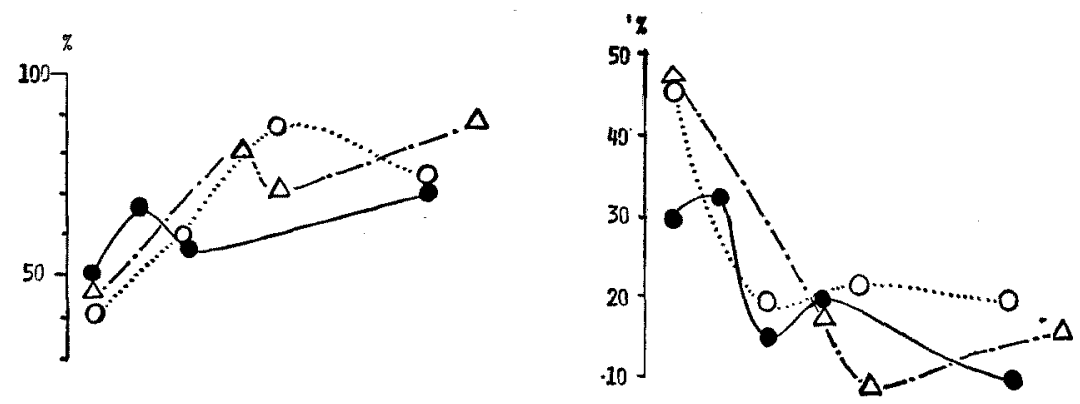

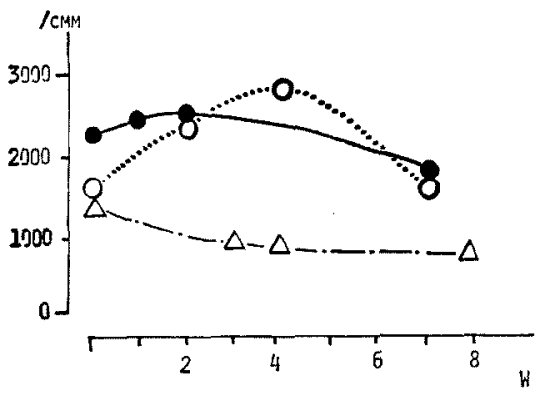

T CELL ( RFC )

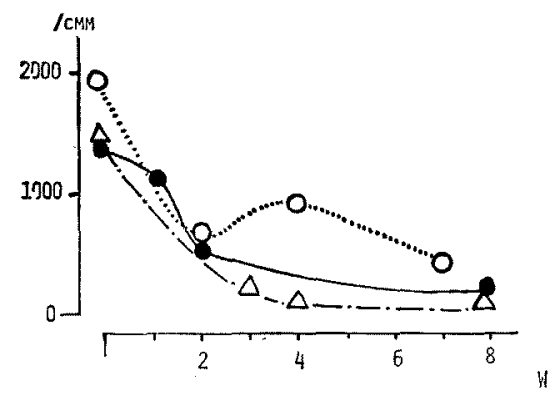

B CELL ( CRL)

Fig. 6 Change in peripheral blood lymphocyte subpopulations during the administration of cyclophosphamide. 

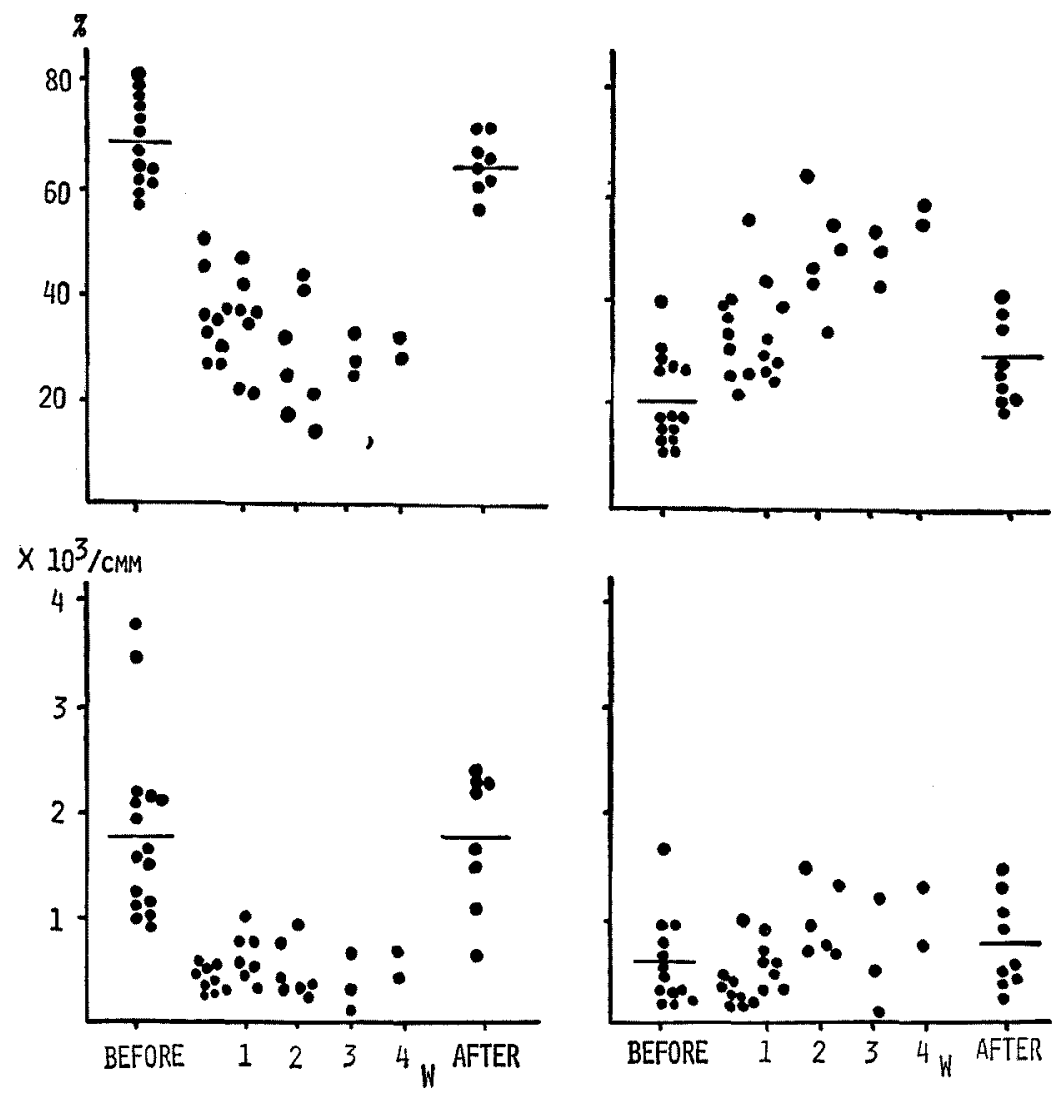

T CELL ( RFC )

B CELL ( SIG )

Fig. 7 Changes in peripheral blood lymphocyte subpopulations during the injection of $\mathrm{ACTH}$.

of E-rosette lymphocytes was noticed in asthmatic patients who had been treated with corticosteroid for a long period and did not respond to ACTH by the increase of plasma cortisol. (Fig. 8)

In vitro lymphocytolysis was not caused by the concentration of hydrocortisone or ACTH which could be reached in the plasma after ACTH-Z injection. It required 100 times more concentrated drugs to induce cytolysis, (Fig. 9)

3) Viral infections:

Lymphocytopenia especially of the E-rosette lymphocyte population was observed during the acute stage of various viral infections except infectious mono- 


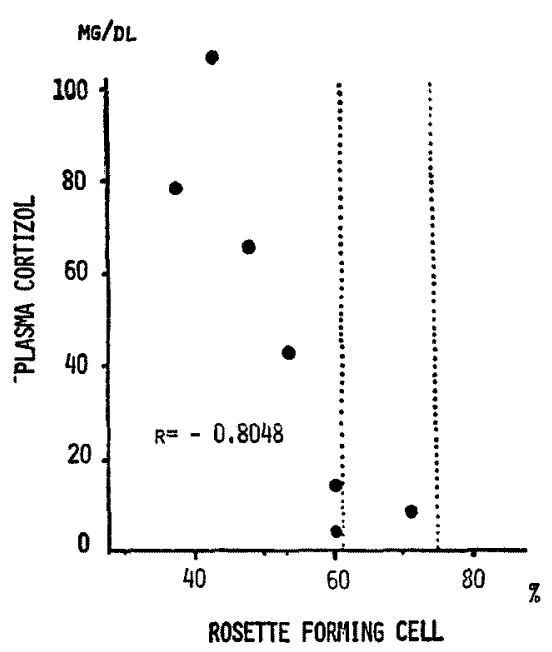

INDIVISUALS WITH NORMAL ADRENAL FUNCTION ( INFANTILE SPASMS )

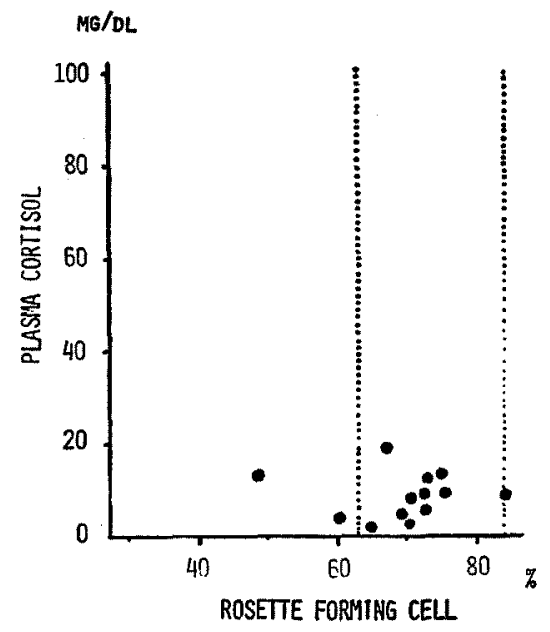

INDIVIDUALS WITH IMPAIRED ADRENAL FUNCTION ( ASTHMATIC PATIENTS TREATED WITH CORTICOSTEROID FOR LONG TIME )

Fig. 8 Relationship between $T$ cell levels and plasma cortizol levels in the peripheral blood from individuals with and without impaired adrenal function who were injected with ACTH.

nucleosis which showed increased $\mathrm{T}$ cells in most cases. (Fig. 10)

Measles caused most severe reduction of E-rosette lymphocytes. This effect persisted for 2-3 weeks. (Fig. 11) In vitro infection of the lymphocytes with measles virus did not affect on the viability of the cells in 7 days' culture, though it caused reduction of phytohaemagglutinin response of the lymphocytes.

\section{DISCUSSION}

The specificity of the four markers has been discussed already..$^{2,7}$ E-rosette and HTLA seem to characterize T cells, while EAC-rosette and S-Ig B cells.

Immunodeficiency in the most of patients with severe combined immunodeficiency seemed to be caused by the block of differentiation of both $\mathrm{T}$ and $\mathrm{B}$ cell series. It seemed possible that $T$ cells present in case 5 did not function well, and therefore their maturation process was not completed. The block of maturation from $B$ cells to antibody forming cells which was observed in case 6 could be due to the intrinsic defect of $B$ cells or altanatively to the insufficiency of helper 

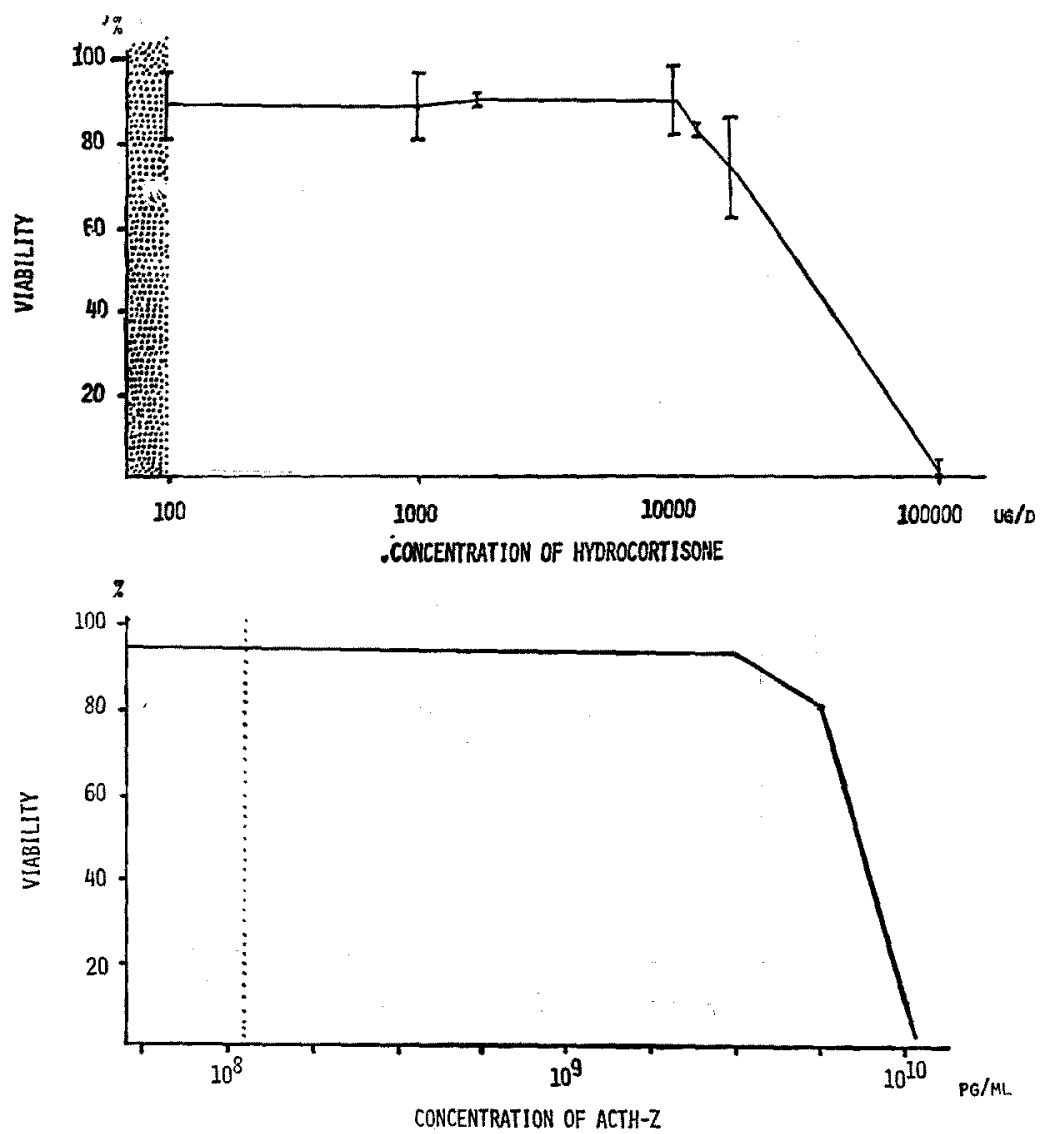

Fig. 9 In vitro cytotoxicity of hydrocortisone and ACTH

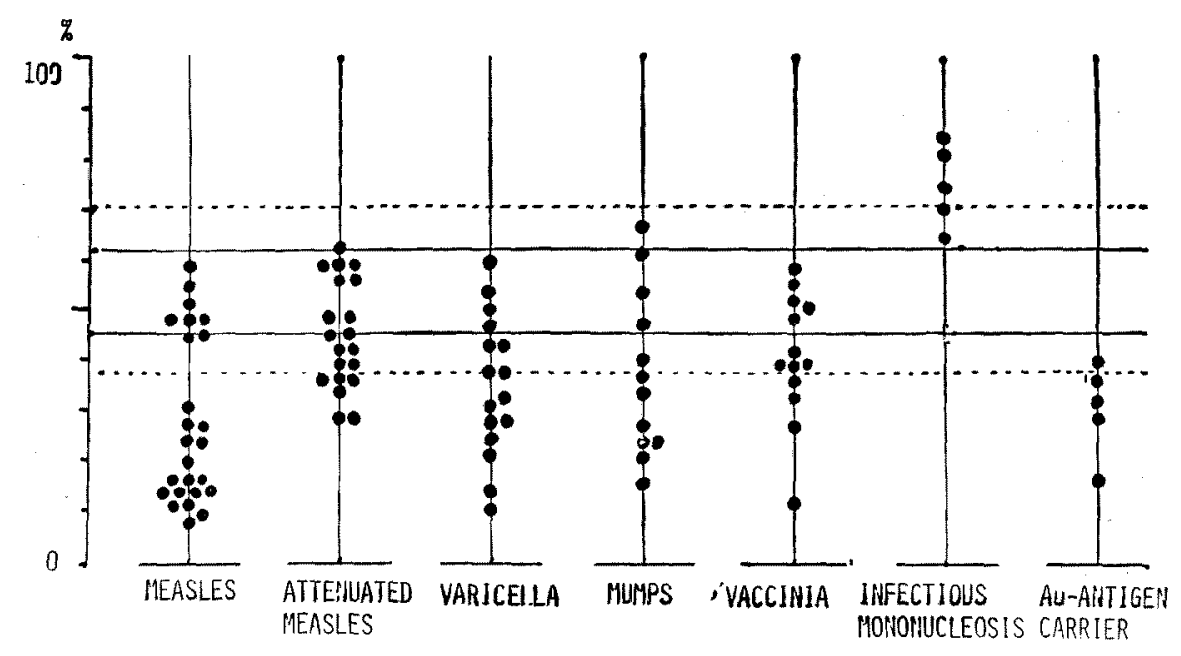




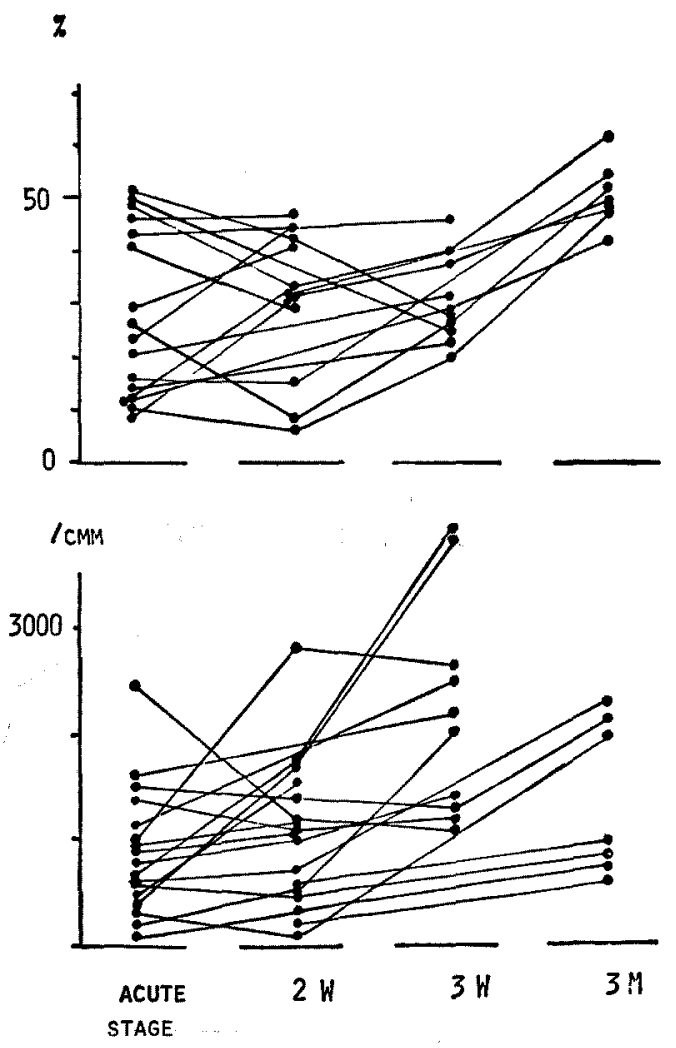

Fig. 11 Changes of E-rosette positive lymphocytes during the course of measles infection.

$T$ cells required for the maturation of $B$ cells. The fact that both $T$ and $B$ cells were almost absent in the brother (case 5) while they were normally present in the sister (case 6) would indicate that immunodeficiency status could be variable even within a family. On the other hand the brothers (case 2 and 3 ) from another family showed almost same prophile of $T$ and $B$ cells.

The lymphoid cells with complement receptor observed in infantile agammaglobulinemia seemed not to be monocytes since peroxydase was not detected in them, nuclear arylsulfatase was positive, complement binding to them was not $\mathrm{Mg}^{++}$dependent and they were not phagocytic. However they did not look like the classical B cells because they were lack of surface immunoglobulin. They could be the $B$ cells at a certain stage of development or altanatively the third 
population of the lymphocytes which have such a function as antibody dependent lymphoid cell mediated cytotoxicity.

The deficiency which exists in the patients with variable immunodeficiency seemed to be mostly the impaired function of $T$ cells and $B$ cells, since both cells were almost normally demonstrated in most cases.

Surface IgA bearing lymphocytes were absent, normally present or increased in isolated IgA deficiency patients. Therefore, various etiology could be the case in this disease category. Some may be due to the absence of $\operatorname{IgA}$ producing cellprecursors (B cells), some can be caused by the block of maturation of $B$ cells to IgA producing cells, and others by the increased destruction of IgA.

Cyclophosphamide is well known to suppress selectively B cells in the experimental animals. 3 Administration of $2 \mathrm{mg} / \mathrm{kg}$.day of the drug caused selective reduction of $B$ cells and relative increase of $T$ cells in the circulating lymphocytes. This would indicate that cyclophosphamide has a specific effect also on human B cells.

Decrease of circulating $T$ cells and relative increase of $B$ cells occurred by the injection of ACTH. This effect was not observed in the asthmatic patients which had been treated with corticosteroid for long time and seemed to have impaired adrenal function. Therefore the effect of ACTH on circulating $T$ cells is likely to be developed via adrenal corticosteroid. It was shown by in vitro study that both ACTH and hydrocortisone the concentrations of which can be attained in the plasma by injection of ACTH did not have cytolytic effect on the lymphocytes. Moreover, the $T$ cells recovered to the initial level as early as 48 hours after ceasation of ACTH. Taking these facts in mind, it seemed possible that the decrease of $T$ cells in the peripheral blood was not due to the lymphocytolysis but rather to the sequestration of circulating $T$ cells to elsewhere. $\mathrm{T}$ cells are known to invade into bone marrow by corticosteroid administration in experimental animals. ${ }^{1}$

Decrease of circulating $\mathrm{T}$ cells was observed during the infection of various viruses, especially measles. Several altanative explanations are possible. Lymphocytolysis by the virus infection could be one reason. However the evidence which support this was not obtained by the in vitro infection study. The virus, even inactivated one, suppressed the in vitro response of the lymphocytes to phytohaemagglutinin, and thus it seemed to cause the disturbance of lymphocyte functions. This may be concerned to the disappearance of peripheral blood $\mathrm{T}$ cells. Nonspecific accumulation of $T$ cells to the inflamatory tissues or lymphoid tissues could be another reason. It is also possible that increased excretion of adrenocorticosteroid cause the sequestration of circulating $T$ cells. The combination of these different mechanisms would be the most probable explanation of 
the decrease of $\mathbf{T}$ cells in the peripheral blood.

\section{REFERENCES}

1. Cohen, J. J.: Changes in lymphocyte circulation after hydrocortisone treatment. In: Cell Interactions, P. 162. Editor: Silvestri, L. North Holland Publishing Co., Amsterdam, 1972

2. Jondal, M., Holm, G. and Wigzell, H.: Surface markers on human T and B lymphocytes. J. Exp. Med. 136: 207, 1972

3. Turk, J. L. and Poulter, L. W.: Selective depletion of lymphoid tissue by cyclophosphamide. Clin. Exp. Immunol. 10: 285, 1972

4. Yata, J., Desgranges, C., Tachibana, T. and de Thé, G.: Separation of human lymphocytes forming spontaneous rosettes with sheep erythrocytes. Biomedicine $19: 475,1973$.

5. Yata, J., Klein, G., Kobayashi, N., Furukawa, T. and Yanagisawa, M.: Human thymus-lymphoid tissue antigen and its presence in leukemia and lymphoma. Clin. Exp. Immunol. 7: 781, 1970

6. Yata, J., Desgranges, C., de Thé, G. and Tachibana, T.: Lymphocytes in infectious mononucleosis. Properties of atypical cells and origin of the lymphoblastoid lines. Biomedicine 19: 479, 1973

7. Yata, J., Tsukimoto, I. and Tachibana, T.: Human lymphocyte subpopulations. Human thymus-lymphoid tissue antigen-positive lymphocytes forming rosettes with sheep erythrocytes and HTL antigen-negative lymphocytes interacting with antigen-antibody-complement complexes. Clin. Exp. Immunol. 14: 319, 1973 